\title{
Under Reporting of Dementia Deaths on Death Certificates: A Systematic Review of Population-based Cohort Studies
}

\author{
Juan Pablo Romero MD;1 Julián Benito-León MD, PhD;1,2,3 \\ Elan D. Louis, MD, MSc; 4, 5, 6, 7
}

From the Department of Neurology, ${ }^{1}$ University Hospital "12 de Octubre", Madrid,Spain; Centro de Investigación Biomédica en Red sobre Enfermedades Neurodegenerativas (CIBERNED), ${ }^{2}$ Spain; Department of Medicine,${ }^{3}$ Complutense University, Madrid, Spain; G.H. Sergievsky Center, ${ }^{4}$ College of Physicians and Surgeons, Columbia University, New York, NY, USA; Department of Neurology, ${ }^{5}$ College of Physicians and Surgeons, Columbia University, New York, NY, USA; Taub Institute for Research on Alzheimer's Disease and the Aging Brain, ${ }^{6}$ College of Physicians and Surgeons, Columbia University, New York, NY, USA; Department of Epidemiology, ${ }^{7}$ Mailman School of Public Health, Columbia; University, New York, NY, USA

Word Count: 227 (abstract), 2,861 (text), 1 table, one figure, and 30 references.

Running Title: Population-Based Studies Examining Dementia Coding in Death Certificates.

Key Words: Death certificates, elderly, epidemiology, population-based study, systematic review. 
Correspondence: Julián Benito-León. Avda. De la Constitución 73, portal 3, $7^{\circ}$ Izquierda, E-28821 Coslada, Madrid, Spain. Email jbenitol@meditex.es

\section{Disclosures:}

Dr. Benito-León reports no disclosures.

Dr. Romero reports no disclosures.

Dr. Louis reports no disclosures.

\section{Authors Roles:}

Dr. Romero (juanpa5@hotmail.com) collaborated in: 1) the conception, organization and execution of the research project; 2) the statistical analysis design, and; 3) and the writing of the manuscript first draft and the review and critique of the manuscript.

Dr. Benito-León (jbenitol@meditex.es) collaborated in: 1) the conception, organization and execution of the research project; 2) the statistical analysis design, and; 3) and the writing of the manuscript first draft and the review and critique of the manuscript.

Dr. Louis (edl2@columbia.edu) collaborated in: 1) the conception, organization of the research project, and; 2) the review and critique of the manuscript. 


\section{Acknowledgments and Funding}

Dr. Benito-León is supported by the National Institutes of Health, Bethesda, MD, USA (R01 NS039422), the Commission of the European Union (grant ICT-2011-287739, NeuroTREMOR), and the Spanish Health Research Agency (grant FIS PI12/01602). Dr. Elan D. Louis has received research support from the National Institutes of Health, Bethesda, MD, USA: NINDS \#R01 NS042859 (principal investigator), NINDS \#R01 NS39422 (principal investigator), NINDS \#T32 NS07153-24 (principal investigator), NINDS \#R01 NS073872 (principal investigator), NINDS \#R21 NS077094 (co-Investigator), and NINDS \#R01 NS36630 (co-Investigator), as well as the Parkinson's disease Foundation (principal investigator). 
Abstract. The purpose of this review is to assess the extent to which dementia is omitted as a cause of death from the death certificates of patients with dementia. A systematic literature search was performed to identify populationbased cohort studies in which all participants were examined or screened for symptoms of dementia with a validated instrument followed by confirmation of any suspected cases with a clinical examination (two-phase investigation). Data were extracted in a standardized manner and assessed through the Strengthening the Reporting of Observational Studies in Epidemiology (STROBE) initiative. Seven studies met the selection criteria. These were from America (5 articles, including 2 from Canada, 2 from the United States, and 1 from Brazil), and Europe (2 articles, including 1 from the United Kingdom, and 1 from Spain). Each met at least $83 \%$ of the STROBE criteria. The reporting of dementia on death certificates was poor in these 7 studies, ranging from $7.2 \%$ $34 \%$. Respiratory or circulatory-related problems were the most frequently reported causes of death among people who were demented but who were not reported as demented on death certificates. The use of death certificates for studying dementia grossly underestimates the occurrence of dementia in the population. The poor reporting of dementia on these certificates suggests a lack of awareness of the importance of dementia as a cause of death among medical personnel. There is an urgent need to provide better education on the importance of codification of dementia on death certificates in order to minimize errors in epidemiological studies on dementia. 


\section{INTRODUCTION}

Since the early 12 th century, death certificates have been an important source of information on population health.[1] Today, nearly 900 years after the introduction of the death certificate, death certificate data continue to be immensely important in shaping our understanding of the health of a population.[1] Death certification, and the specification of the underlying cause of death, has been used to map the geographical distribution of multiple diseases. For example, dementia has been studied in this way. Death certificates have been used as a data source to address both the prevalence and incidence of dementia[2] as well as the causes of death associated with dementia. In both of these areas, however, the utility of death certificate data may be limited.[3]

In view of the importance of the subject matter, and the absence of a comprehensive review of the validity of death certificates with respect to dementia, we undertook a systematic review with the aim to determine the extent to which dementia is omitted as a cause of death from the death certificate in patients with known dementia. We included population-based cohort studies in which (i) all participants had been examined to detect dementia cases or (ii) in which participants had been screened for symptoms of dementia with a validated instrument and subsequent confirmation of any suspected dementia cases with a clinical examination (two-phase investigation). 


\section{MATERIAL AND METHODS}

\section{Search Strategy and Information Sources}

Searches were performed in December 2013 using PUBMED/MEDLINE and Google Scholar. The keywords were different combinations of "dementia", "death certificates", and "Alzheimer's disease". In addition, our own extensive files were searched. Original articles were obtained, and all reference lists were scanned for further relevant articles. No time limit was applied in our search strategy. The final list was reviewed by two authors (J.P.R. and J.B.-L.) to identify additional studies or unpublished data.

\section{Inclusion and Exclusion Criteria}

We included population-based cohort studies in which (i) all participants had been examined to detect dementia cases or (ii) in which participants had been screened for symptoms of dementia with a validated instrument and subsequent confirmation of any suspected dementia cases with a clinical examination (two-phase investigation). We excluded studies based on inpatient databases or clinical series. No language restrictions were applied.

\section{Data Extraction}

Two investigators (J.P.R. and J.B.-L.) independently reviewed the title and abstract of all citations identified by the initial search and excluded citations that clearly did not meet the inclusion criteria. We retrieved the full text of the remaining studies and both investigators reviewed each study to assess whether it met the inclusion criteria. All differences were settled by discussion. For each study, data were abstracted on the design, population size, and 
clinical diagnostic methods. The outcome of this systematic review was the concordance of cause of death codification (as coded on the death certificate) with clinical diagnosis of dementia; this concordance was expressed as a percentage.

The selected articles were also evaluated to assess whether they conformed to the Strengthening the Reporting of Observational Studies in Epidemiology (STROBE) recommendations, which seek to assess clarity in the description of epidemiological studies.[4] The STROBE includes 22 items that are related to the information that must be present in the title, abstract, introduction, methods, results, and discussion of scientific articles describing observational studies.[4]

\section{Statistical analysis}

For the evaluation of article selection criteria and study quality among reviewers, the kappa-measured agreement was based on the specifications of the specialized literature: $k<0.10$, no agreement; $k<0.40$, weak agreement; $0.40<k<0.75$, good agreement; $k>0.75$, excellent agreement.[5]

\section{RESULTS}

The electronic search identified a total of 170 articles, of which 7 articles met our inclusion criteria.[6-12] Because the independent selection of articles for inclusion in this review showed excellent agreement $(k=0.970)$, the intervention of a third researcher was not required. Figure 1 shows the progressive selection procedure and the number of articles at each step. 


\section{Description of studies}

The seven articles that met the specific inclusion criteria at the end of the selection procedure included five from America (2 from Canada, 2 from the United States, and 1 from Brazil), and two from Europe (1 from the United Kingdom, and 1 from Spain). The sample size of the studies ranged from 527 to 10,263 participants. Overall, the reporting of dementia on death certificates in these 7 studies was poor, ranging from 7.2 to $34 \%$ (Table 1). Four articles reported results from two cohorts (the Monongahela Valley Independent Elders Survey [MoVIES] and the Canadian Study of Health and Aging).[7-10] Table 1 summarizes the diagnostic criteria used for dementia as well as the causes of death among those who were demented but who were not reported as demented on death certificates. Respiratory or circulatory-related problems were the most frequently reported causes of death in these people.

Of 1,042 elderly people, randomly selected by Morgan and Clarke,[6] there were 512 deaths in the period from 1985-1994, with 44 of these deaths occurring among respondents who, at clinical interview, met Diagnostic and Statistical Manual of Mental Disorders, 3rd Edition—Revised (DSM-III-R) criteria for dementia.[13] The presence of dementia, however, was recorded on only 15 (34\%) of the 44 death certificates.[6] This low level of recording was not significantly related to the patient's gender, age, or place of death (i.e., at a private home vs. at an institution). Also, earlier (1985-1990) and later (19901994) certificates showed similar levels of non-recording.[6]

Ganguli and Rodríguez[9] used a prospective epidemiological study in which community-dwelling elderly subjects with and without dementia $(\mathrm{N}=$ 1,422, the MoVIES study) were identified and followed until death, after which 
their death certificates were examined.[9] The cohort was established between 1987 and 1989, and mortality data were reported as of December 31, 1996.[9] Death certificates were examined for a total of 527 deceased participants, including 172 individuals to whom research diagnoses of dementia had been assigned during life applying DSM-III-R criteria.[9] Of these 172 deceased subjects, conditions indicating or suggesting dementia were reported in $23.8 \%$ of death certificates.[9] In a multiple logistic regression model, variables associated independently with the reporting of dementia in demented individuals were: greater severity of dementia, likely etiology of dementia (probable Alzheimer's disease more frequently reported), and dying in a longterm care institution.[9]

Østbye et al.[7], using data from the Canadian Study of Health and Aging, compared 5-year overall mortality and causes of death in elderly with and without dementia. The cohort consisted of 2,923 people who underwent a clinical examination and 7,340 people who screened negative for cognitive impairment and did not undergo a clinical examination.[7] Among patients clinically diagnosed with Alzheimer's disease, only $14.3 \%$ had any dementing illness recorded as the underlying cause of death; $41.8 \%$ had any dementing illness recorded anywhere on the death certificate.[7] For vascular dementia, the corresponding numbers were $5.8 \%$ and $23.3 \%$.[7]

Chamandy and Wolfson [10] also examined the associations between clinical dementia and underlying cause of death in the Canadian Study of Health and Aging. However, the methods were slightly different from the paper by Østbye et al.[7] who previously examined cause of death in the cohort, but in the context of a larger analysis and a coarser partition of causes of death (e.g., 
pneumonia was not differentiated from chronic respiratory conditions). Cause-of death data were obtained via death certificates for 2,924 of 2,982 deceased subjects. Among 754 demented, $7.2 \%$ were coded as Alzheimer's disease in death certificates.[10]

Ganguli et al.,[8] examined mortality rates, duration of survival, causes of death, and the contribution of Alzheimer's disease to the risk of mortality in the MoVIES study, a community-based cohort of 1,670 elderly adults $(1,422$ randomly selected from voter registration lists and an additional 259 volunteers from the same area).[8] Mortality data were reported as of December 31, 2002. Only $29(12.3 \%)$ of the 236 participants with Alzheimer's disease had this condition reported in their death certificate.[8]

Nitrini et al.,[11] studied a cohort of 1,656 elderly individuals who were screened for dementia at their homes in 1997. The same population was reevaluated in 2000, and information on deaths was obtained from relatives and from the municipal obituary service.[11] As of 1997, the number of deaths was $58(51.3 \%)$ among the patients with dementia and $163(12.7 \%)$ among those without dementia. Dementia and/or Alzheimer's disease were mentioned in only $12.5 \%$ of the death certificates of individuals with dementia.[11]

Finally, Romero at al.,[12] in a prospective population-based study (NEDICES), using a two-phase approach involving 4,197 community-dwelling elderly subjects with and without dementia followed during a median of 12.5 years, examined the death certificates of those who died $(1,976$ [47.1\%], including 403 subjects with dementia). Dementia was rarely reported as the primary cause of death, even in known cases of dementia (20.8\%).[12] Specifically, it was reported in only $13.3 \%$ of those with mild dementia and 
$24.3 \%$ of those with moderate or severe dementia; in $24.9 \%$ of those with possible or probable Alzheimer's disease; and in $11.9 \%$ of those with nonAlzheimer dementia.[12] In a stepwise multiple logistic regression analysis with the dependent variable being presence or absence of dementia on the death certificate, age at death, severity of dementia, and etiology of dementia were the significantly associated independent variables.[12]

\section{Quality of studies}

The evaluation of agreement between the evaluators (J.P.R. and J.B.-L.) in the classification of articles, according to the STROBE criteria showed excellent agreement $(k=0.758)$. All articles met at least $83 \%$ of the STROBE criteria (Table 2). All of them stated the specific objectives. In addition, the key elements of the study design and main results were presented in all seven articles (Table 2). 


\section{DISCUSSION}

In this review of population-based studies published up to December 2013 in PubMed/Medline and Google Scholar databases, we tried to elucidate the extent to which dementia is omitted as a cause of death from death certificates. We restricted our analysis to population-based cohort studies in which all participants were examined or in which all participants were screened for symptoms of dementia with a validated instrument followed by a confirmation of any suspected cases with a clinical examination (two-phase investigation). We focused on these types of studies because, unlike clinical series or hospital registries, these tended to include even those with previously undiagnosed dementia residing in the population.

Our conclusions are as follows. First, there are very few studies (seven in total) meeting these criteria. Second, all studies we included met the majority of required items from the STROBE guidelines. Finally, dementia was reported in fewer than one third of the deaths of community-dwelling demented individuals.

Three of the studies assessed whether a broad range of variables was correlated with the reporting of dementia on death certificates.[6, 9, 12] Dementia was significantly more likely to be reported in more advanced dementia, those with probable Alzheimer's disease, younger patients, and those who die in nursing homes. However, gender does not appear to influence this reporting. In a British series of death certificates of early onset-cases from hospital-case records, Newens et al.,[14] found that dementia was more likely to be underreported in men; by contrast, in other clinical series, such as CERAD, 
dementia was significantly less likely to be certified in women who had been diagnosed as having Alzheimer's disease.[15]

With respect to age at death, the results are not consistent. In the NEDICES study, among those died before 85 years, compared to those aged 85 and over, the odds that dementia was reported on death certificates was 2.33, 95\%, confidence interval (1.33-4.10), $\mathrm{p}=0.003$. This suggests that physicians may consider cognitive disorders to be a function of normal ageing and not diagnose dementia in their oldest patients. In CERAD, age at death was not related to under reporting of dementia on death certificates.[15]

All of the included cohorts were ethnically homogeneous.[6-12] This did not allow us to analyse the impact of race on reporting; however, in clinical series, dementia was significantly less likely to be certified in blacks.[15]

Dementia seems more likely to be listed on death certificates of individuals who had been clinically diagnosed with Alzheimer's disease or probable Alzheimer's disease than those diagnosed as other non- Alzheimer's disease dementias. $[9,12]$ This is in line with the results from other dementia registries.[16-18] This may reflect a lack of recognition of dementia in the context of stroke or a displacement of dementia from the death certificate by the underlying vascular causes of both death and dementia, mainly cerebrovascular diseases. With respect to severity of dementia, higher severity of dementia was associated with higher odds of reporting dementia in the death certificates, $[9$, 12] similar to clinical series.[19] The certifying physician might be less likely to have documented dementia when the disorder is mild.[14] In other words, mild dementia may be less likely to be listed on death certificates because its 
presence is less evident to the certifying physician. It is widely known that severe dementia increases the mortality risk through immobility, swallowing disorders, incontinence, and malnutrition.[9, 20] However, physicians may not report dementia, even when they are aware of the severity of dementia, if they do not feel to be underlying or contributing to the patient's death.[9] The aforementioned complications of severe dementia, in turn, underlie more immediate causes of death, including pneumonia.[10, 16, 18, 21] Further, common comorbid disorders in the elderly, such as heart disease, stroke, hip fractures, and chronic obstructive lung disease are in general better accepted as causes of death. In other reported conditions, such as Parkinson's disease, cognitive problems, including dementia, are often observed.[22, 23] If death certificates data are to be used to estimate mortality from dementing disorders, it may be useful to simultaneously search for documentation of other reported central nervous system conditions likely to be associated with dementia.[9]

Dementia is more often reported for the demented who die in psychiatric and geriatric facilities.[9] It seems logical that nursing homes have more patients with more severe and full-blown dementia and therefore physicians attending those centers are more likely to report dementia on death certificates.[24]

Although regional or national differences in diagnostic accuracy of conditions reported on death certificates have been suggested, with European rates higher than rates in the USA, $[16,18,21]$ the rates of the present review are similar. Thus, in the MoVIES study, conducted in the USA, conditions 
indicating or suggesting dementia was reported in $23.8 \%$ of death certificates vs. $20.8 \%$ in the Spanish NEDICES study.[9, 12]

In the last years, dementia awareness has increased among both physicians and the public, in general. Previous surveys have found that the frequency with which dementia was recorded on death certificates increased significantly over the years of their study.[14, 15] However, the period during which death certificates were completed did not influence the rate of reporting in the MoVIES and NEDICES studies,[9, 12] or in Morgan and Clarke's study,[6].

Increased awareness of medical staff regarding the mortality and morbidity associated with dementia could lessen the degree of under reporting. For example, in the CERAD study, in the first wave, only $49 \%$ endorsed dementia versus $65 \%$ in the second wave $(p<0.025)$,[15] suggesting that greater awareness among the medical staff could result in increased coding of dementia as a cause of death. Of interest, none of the studies assessed who signed the death certificate (i.e., general physician versus neurologist or geriatrician). It is logical to assume that the level of expertise of the physician who signed the death certificate might predict the level of accuracy of that certificate.

This study had potential limitations. Database restriction and the search strategy may have excluded important studies that were not published in the data sources we searched, although we used multiple overlapping study identification methods, so this is not likely. 
In closing, the use of death certificates for studying dementia grossly underestimates the occurrence of dementia in the population. The poor reporting of dementia on these certificates suggests a lack of awareness of the importance of dementia as a cause of death among medical personnel. There is an urgent need to provide better education on the importance of codification of dementia on death certificates in order to minimize errors in epidemiological studies on dementia.

\section{References}

[1] Riedl B, Than N, Hogarth M (2010) Using the UMLS and Simple Statistical Methods to Semantically Categorize Causes of Death on Death Certificates. AMIA Annu Symp Proc 2010, 677-681.

[2] Chandra V, Bharucha NE, Schoenberg BS (1986) Patterns of mortality from types of dementia in the United States, 1971 and 1973-1978. Neurology 36, 204-208.

[3] Martyn CN, Pippard EC (1988) Usefulness of mortality data in determining the geography and time trends of dementia. J Epidemiol Community Health 42, 134-137.

[4] von Elm E, Altman DG, Egger M, Pocock SJ, Gotzsche PC, Vandenbroucke JP, Initiative S (2007) Strengthening the Reporting of Observational Studies in Epidemiology (STROBE) statement: guidelines for reporting observational studies. BMJ 335, 806-808.

[5] Mandrekar JN (2011) Measures of interrater agreement. J Thorac Oncol 6, 6-7.

[6] Morgan K, Clarke D (1995) To what extent is dementia underreported on british death certificates? Int J Geriatr Psychiatry 10, 987-990.

[7] Ostbye T, Hill G, Steenhuis R (1999) Mortality in elderly Canadians with and without dementia: a 5-year follow-up. Neurology 53, 521-526.

[8] Ganguli M, Dodge HH, Shen C, Pandav RS, DeKosky ST (2005) Alzheimer disease and mortality: a 15-year epidemiological study. Arch Neurol 62, 779-784.

[9] Ganguli M, Rodriguez EG (1999) Reporting of dementia on death certificates: a community study. J Am Geriatr Soc 47, 842-849.

[10] Chamandy N, Wolfson C (2005) Underlying cause of death in demented and nondemented elderly Canadians. Neuroepidemiology 25, 75-84.

[11] Nitrini R, Caramelli P, Herrera E, Jr., de Castro I, Bahia VS, Anghinah R, Caixeta LF, Radanovic M, Charchat-Fichman H, Porto CS, Teresa Carthery M, Hartmann APJ, Huang N, Smid J, Lima EP, Takahashi DY, Takada LT (2005) Mortality from dementia in a community-dwelling Brazilian population. Int J Geriatr Psychiatry 20, 247-253.

[12] Romero JP, Benito-Leon J, Mitchell AJ, Trincado R, Bermejo-Pareja F (2013) Under Reporting of Dementia Deaths on Death Certificates using Data from A PopulationBased Study (NEDICES). J Alzheimers Dis.

[13] American Psychiatric A (1987) DSM-III-RDiagnostic and Statistical Manual of Mental Disorder, Washington DC. 
[14] Newens AJ, Forster DP, Kay DW (1993) Death certification after a diagnosis of presenile dementia. J Epidemiol Community Health 47, 293-297.

[15] Raiford K, Anton-Johnson S, Haycox Z, Nolan K, Schaffer A, Caimano C, Fillenbaum G, Heyman A (1994) CERAD part VII: accuracy of reporting dementia on death certificates of patients with Alzheimer's disease. Neurology 44, 2208-2209.

[16] Molsa PK, Marttila RJ, Rinne UK (1986) Survival and cause of death in Alzheimer's disease and multi-infarct dementia. Acta Neurol Scand 74, 103-107.

[17] Macera CA, Sun RK, Yeager KK, Brandes DA (1992) Sensitivity and specificity of death certificate diagnoses for dementing illnesses, 1988-1990. J Am Geriatr Soc 40, 479-481.

[18] Thomas BM, Starr JM, Whalley LJ (1997) Death certification in treated cases of presenile Alzheimer's disease and vascular dementia in Scotland. Age Ageing 26, 401406.

[19] Kukull WA, Brenner DE, Speck CE, Nochlin D, Bowen J, McCormick W, Teri L, Pfanschmidt ML, Larson EB (1994) Causes of death associated with Alzheimer disease: variation by level of cognitive impairment before death. J Am Geriatr Soc 42, 723-726.

[20] Villarejo A, Benito-León J, Trincado R, Posada IJ, Puertas-Martín V, Boix R, Medrano MRAJ, Bermejo-Pareja $F$ (2011) Dementia-associated mortality at thirteen years in the NEDICES Cohort Study. Journal of Alzheimer's disease: JAD 26, 543-551.

[21] Burns A, Jacoby R, Luthert P, Levy R (1990) Cause of death in Alzheimer's disease. Age Ageing 19, 341-344.

[22] Posada IJ, Benito-Leon J, Louis ED, Trincado R, Villarejo A, Medrano MJ, BermejoPareja $F$ (2011) Mortality from Parkinson's disease: a population-based prospective study (NEDICES). Mov Disord 26, 2522-2529.

[23] Benito-Leon J, Louis ED, Posada IJ, Sanchez-Ferro A, Trincado R, Villarejo A, Mitchell AJ, Bermejo-Pareja $F$ (2011) Population-based case-control study of cognitive function in early Parkinson's disease (NEDICES). J Neurol Sci 310, 176-182.

[24] Olichney JM, Hofstetter CR, Galasko D, Thal L, Katzman R (1995) Death certificate reporting of dementia and mortality in an Alzheimer's disease research center cohort. J Am Geriatr Soc 43, 890-893.

[25] Messite J, Stellman SD (1996) Accuracy of death certificate completion: the need for formalized physician training. JAMA 275, 794-796.

[26] Bermejo-Pareja F, Benito-León J, Vega S, Olazarán J, de Toledo M, Díaz-Guzmán J, Sánchez-Sánchez F, Morales-González JM, Trincado R, Portera-Sánchez A, Román GC (2009) Consistency of clinical diagnosis of dementia in NEDICES: A population-based longitudinal study in Spain. J Geriatr Psychiatry Neurol 22, 246-255.

[27] Bermejo-Pareja F, Benito-León J, Vega S, Medrano MJ, Román GC (2008) Incidence and subtypes of dementia in three elderly populations of central Spain. J Neurol Sci 264, 63-72.

[28] Ritchie K, Kildea D (1995) Is senile dementia "age-related" or "ageing-related"?-evidence from meta-analysis of dementia prevalence in the oldest old. Lancet 346, 931-934.

[29] Kohn RR (1982) Cause of death in very old people. JAMA 247, 2793-2797.

[30] Attems J, Arbes S, Bohm G, Bohmer F, Lintner F (2004) The clinical diagnostic accuracy rate regarding the immediate cause of death in a hospitalized geriatric population; an autopsy study of 1594 patients. Wien Med Wochenschr 154, 159-162. 
Table 1: Main characteristics of the selected studies

\begin{tabular}{|l|l|l|l|}
\hline Reference & $\begin{array}{l}\text { Diagnostic criteria } \\
\text { for dementia }\end{array}$ & $\begin{array}{l}\text { Reporting of dementia } \\
\text { on death certificates }\end{array}$ & $\begin{array}{l}\text { Causes of death in those who were demented but who were not reported } \\
\text { as demented on death certificates }\end{array}$ \\
\hline $\begin{array}{l}\text { Morgan and } \\
\text { Clarke., 1995 }\end{array}$ & DSM-III-R & $\begin{array}{l}34 \% \text { (as an associated } \\
\text { underlying condition) }\end{array}$ & $\begin{array}{l}\text { Broncho-pneumonia (72.1\%); cerebrovascular disease (11.6\%); heart disease } \\
(9.1 \%) ; \text { cancer (4.6\%); sepsis (2.3\%) }\end{array}$ \\
\hline $\begin{array}{l}\text { Ganguli and } \\
\text { Rodríguez., } 1999\end{array}$ & DSM-III-R & $23.8 \%$ & Not reported \\
\hline Østbye et al., 1999 & DSM-III-R & $\begin{array}{l}41.8 \% \text { of Alzheimer's } \\
\text { disease patients. } \\
23.3 \% \text { of vascular } \\
\text { dementia patients }\end{array}$ & $\begin{array}{l}\text { Most deaths in people with dementia were due to diseases of the respiratory or } \\
\text { circulatory systems (yet percentages were not reported) }\end{array}$ \\
\hline $\begin{array}{l}\text { Chamandy and } \\
\text { Wolfson., 2005 }\end{array}$ & DSM-III-R & disease) & $\begin{array}{l}\text { Ischemic heart disease (19.2\%); other heart/circulatory system disease } \\
(13.3 \%) ; \text { cerebrovascular disease (13.1\%); pneumonia (12.3\%); cancer } \\
(10.7 \%) ; \text { chronic respiratory disease (4.2\%) }\end{array}$ \\
\hline Ganguli et al., 2005 & DSM-III-R & $\begin{array}{l}12.3 \% \text { of Alzheimer's } \\
\text { disease patients }\end{array}$ & $\begin{array}{l}\text { Cardiovascular (47.5\%); respiratory (22.5\%); cancer (12.3\%); other brain } \\
\text { disorder (5.5\%); genitourinary (5.5\%); gastrointestinal (4.7\%); unknown "natural } \\
\text { causes" (2.1\%); miscellaneous (10.2\%) }\end{array}$ \\
\hline Nitrini et al., 2005 & DSM-IV & $\begin{array}{l}\text { Pneumonia (40.0\%); respiratory failure (27.5\%); heart failure }(20.0 \%) ; \text { sepsis } \\
(20.0 \%) ; \text { stroke (20.0\%); cancer (17.5\%); cardiorespiratory arrest (15\%); renal } \\
\text { failure (12.5\%); arrhythmia (10\%); pulmonary embolism (7.5\%); acute } \\
\text { myocardial infarction (5.0\%); coronary artery disease (5.0\%) }\end{array}$ \\
\hline $\begin{array}{l}\text { Romero et al., } \\
2013\end{array}$ & DSM-IV & $\begin{array}{l}\text { Cerebrovascular disorders (13.4\%); cardiovascular diseases (27.5\%); } \\
\text { respiratory diseases (14.4\%); cancer (6.0\%); other causes (17.9\%) }\end{array}$ \\
\hline
\end{tabular}

Diagnostic and Statistical Manual of Mental Disorders, 3rd Edition-Revised (DSM-III-R)

Diagnostic and Statistical Manual of Mental Disorders, 4th Edition (DSM-IV) 
Table 2: Strengthening the Reporting of Observational Studies in Epidemiology (STROBE) recommendations and reported percentages of observational studies.

\begin{tabular}{|c|c|c|c|c|c|c|c|c|c|c|}
\hline & & Recommendation & 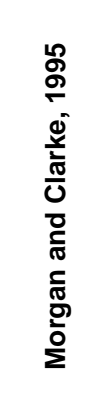 & 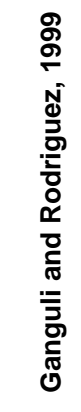 & 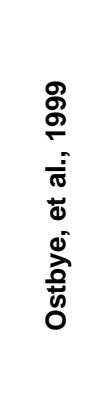 & 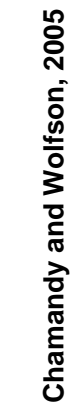 & 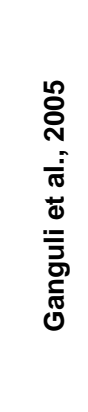 & 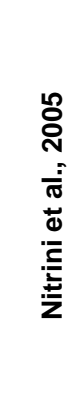 & 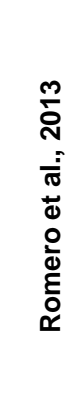 & 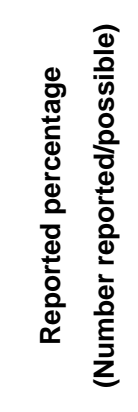 \\
\hline \multirow[t]{2}{*}{$\begin{array}{l}\text { Title and } \\
\text { abstract }\end{array}$} & \multirow[t]{2}{*}{ Title and abstract } & $\begin{array}{l}\text { (a) Indicate the study's design with a commonly used term in the title } \\
\text { or the abstract }\end{array}$ & $X$ & $\mathrm{X}$ & $\mathrm{X}$ & $\mathrm{X}$ & $\mathrm{X}$ & $X$ & $\mathrm{X}$ & $7 / 7(100 \%)$ \\
\hline & & $\begin{array}{l}\text { (b) Provide in the abstract an informative and balanced summary of } \\
\text { what was done and what was found }\end{array}$ & $\mathrm{X}$ & $\mathrm{X}$ & $\mathrm{X}$ & $\mathrm{X}$ & $\mathrm{X}$ & $\mathrm{X}$ & $\mathrm{X}$ & $7 / 7(100 \%)$ \\
\hline \multirow[t]{2}{*}{ Introduction } & Background/rationale & $\begin{array}{l}\text { Explain the scientific background and rationale for the investigation } \\
\text { being reported }\end{array}$ & $\mathrm{X}$ & $\mathrm{X}$ & $\mathrm{X}$ & $\mathrm{X}$ & $\mathrm{X}$ & $\mathrm{X}$ & $\mathrm{X}$ & $7 / 7(100 \%)$ \\
\hline & Objectives & State specific objectives, including any prespecified hypotheses & $\mathrm{X}$ & $\mathrm{X}$ & $\mathrm{X}$ & $\mathrm{X}$ & $\mathrm{X}$ & $\mathrm{X}$ & $\mathrm{X}$ & $7 / 7(100 \%)$ \\
\hline \multirow[t]{12}{*}{ Methods } & Study design & Present key elements of study design early in the paper & $\mathrm{X}$ & $\mathrm{X}$ & $\mathrm{X}$ & $\mathrm{X}$ & $\mathrm{x}$ & $\mathrm{X}$ & $\mathrm{x}$ & $7 / 7(100 \%)$ \\
\hline & Setting & $\begin{array}{l}\text { Describe the setting, locations, and relevant dates, including periods of } \\
\text { recruitment, exposure, follow-up, and data collection }\end{array}$ & $x$ & $x$ & $x$ & $x$ & $x$ & $x$ & $x$ & $7 / 7(100 \%)$ \\
\hline & Participants & $\begin{array}{l}\text { Give the eligibility criteria, and the sources and methods of selection of } \\
\text { participants. Describe methods of follow-up }\end{array}$ & $\mathrm{X}$ & $\mathrm{X}$ & $\mathrm{X}$ & $\mathrm{X}$ & $\mathrm{X}$ & $X$ & $\mathrm{X}$ & $7 / 7(100 \%)$ \\
\hline & Variables & $\begin{array}{l}\text { Clearly define all outcomes, exposures, predictors, potential } \\
\text { confounders, and effect modifiers. Give diagnostic criteria, if applicable }\end{array}$ & $\mathrm{X}$ & $\mathrm{X}$ & $\mathrm{X}$ & $\mathrm{X}$ & $\mathrm{X}$ & $\mathrm{X}$ & $\mathrm{X}$ & $7 / 7(100 \%)$ \\
\hline & $\begin{array}{l}\text { Data sources/ } \\
\text { measurement }\end{array}$ & $\begin{array}{l}\text { For each variable of interest, give sources of data and details of } \\
\text { methods of assessment (measurement). Describe comparability of } \\
\text { assessment methods if there is more than one group }\end{array}$ & $\mathrm{X}$ & $\mathrm{X}$ & $\mathrm{X}$ & $\mathrm{X}$ & $\mathrm{X}$ & $\mathrm{X}$ & $\mathrm{X}$ & $7 / 7(100 \%)$ \\
\hline & Bias & Describe any efforts to address potential sources of bias & $\mathrm{X}$ & $\mathrm{X}$ & $\mathrm{X}$ & $\mathrm{X}$ & $\mathrm{X}$ & $\mathrm{X}$ & $\mathrm{X}$ & $7 / 7(100 \%)$ \\
\hline & Study size & Explain how the study size was arrived at & $\mathrm{X}$ & $\mathrm{X}$ & $\mathrm{X}$ & $\mathrm{X}$ & $\mathrm{X}$ & $\mathrm{X}$ & $\mathrm{X}$ & $7 / 7(100 \%)$ \\
\hline & Quantitative variables & $\begin{array}{l}\text { Explain how quantitative variables were handled in the analyses. If } \\
\text { applicable, describe which groupings were chosen and why }\end{array}$ & $\mathrm{X}$ & $\mathrm{X}$ & $\mathrm{X}$ & $\mathrm{X}$ & $\mathrm{X}$ & $\mathrm{X}$ & $\mathrm{X}$ & $7 / 7(100 \%)$ \\
\hline & \multirow[t]{4}{*}{ Statistical methods } & $\begin{array}{l}\text { (a) Describe all statistical methods, including those used to control for } \\
\text { confounding }\end{array}$ & $\mathrm{X}$ & $\mathrm{X}$ & $\mathrm{X}$ & $\mathrm{X}$ & $\mathrm{X}$ & $\mathrm{X}$ & $\mathrm{X}$ & $7 / 7(100 \%)$ \\
\hline & & (b) Describe any methods used to examine subgroups and interactions & $\mathrm{X}$ & $\mathrm{X}$ & $\mathrm{X}$ & $\mathrm{X}$ & $\mathrm{X}$ & $\mathrm{X}$ & $\mathrm{X}$ & $7 / 7(100 \%)$ \\
\hline & & (c) Explain how missing data were addressed & $\mathrm{X}$ & $\mathrm{X}$ & $\mathrm{X}$ & $\mathrm{X}$ & $\mathrm{X}$ & $\mathrm{X}$ & $\mathrm{X}$ & $7 / 7(100 \%)$ \\
\hline & & (d) If applicable, explain how loss to follow-up was addressed & $\mathrm{X}$ & $\mathrm{X}$ & $\mathrm{X}$ & $\mathrm{X}$ & $\mathrm{X}$ & $\mathrm{X}$ & $\mathrm{X}$ & $7 / 7(100 \%)$ \\
\hline Results & Participants & $\begin{array}{l}\text { (a) Report numbers of individuals at each stage of study-e.g. } \\
\text { numbers potentially eligible, examined for eligibility, confirmed eligible, }\end{array}$ & $\mathrm{X}$ & $\mathrm{X}$ & $\mathrm{X}$ & $\mathrm{X}$ & $\mathrm{X}$ & $\mathrm{X}$ & $\mathrm{X}$ & $7 / 7(100 \%)$ \\
\hline
\end{tabular}




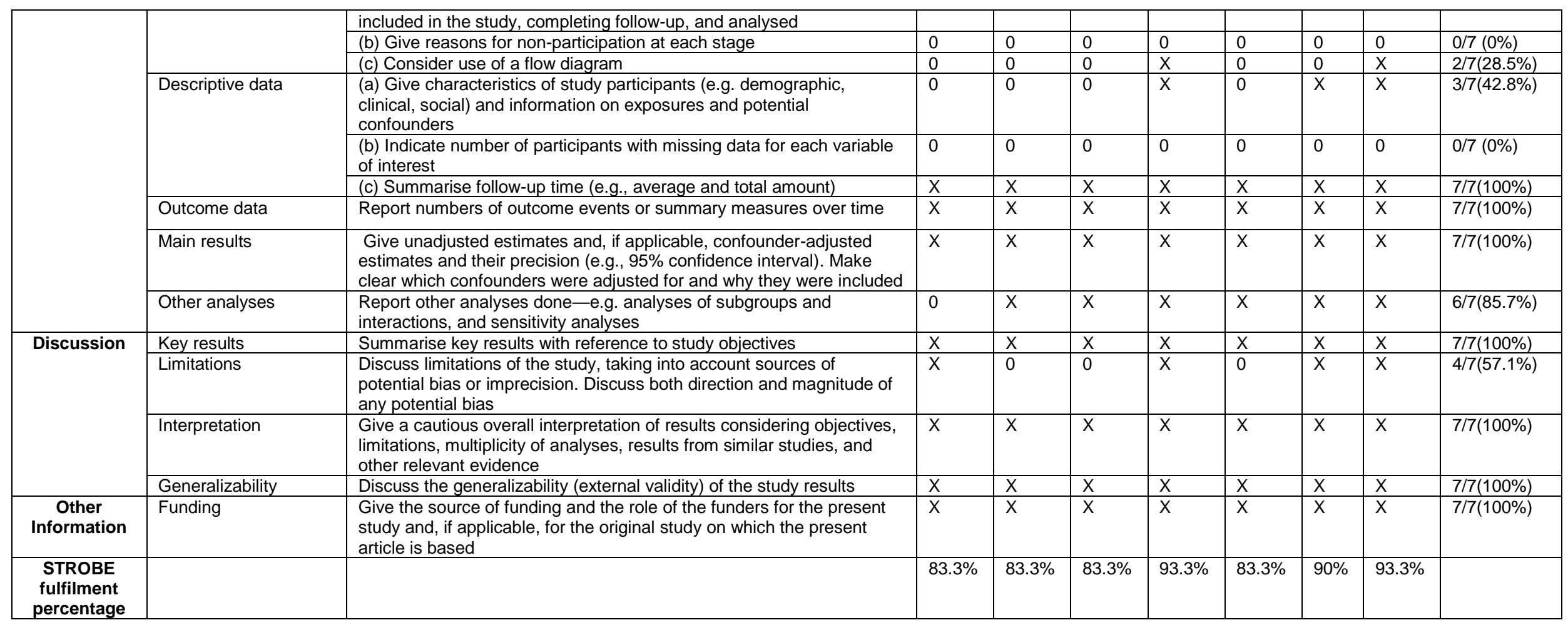

Information on the STROBE Initiative is available at http://www.strobe-statement.org. 
Figure 1: Identification of studies in the systematic review.

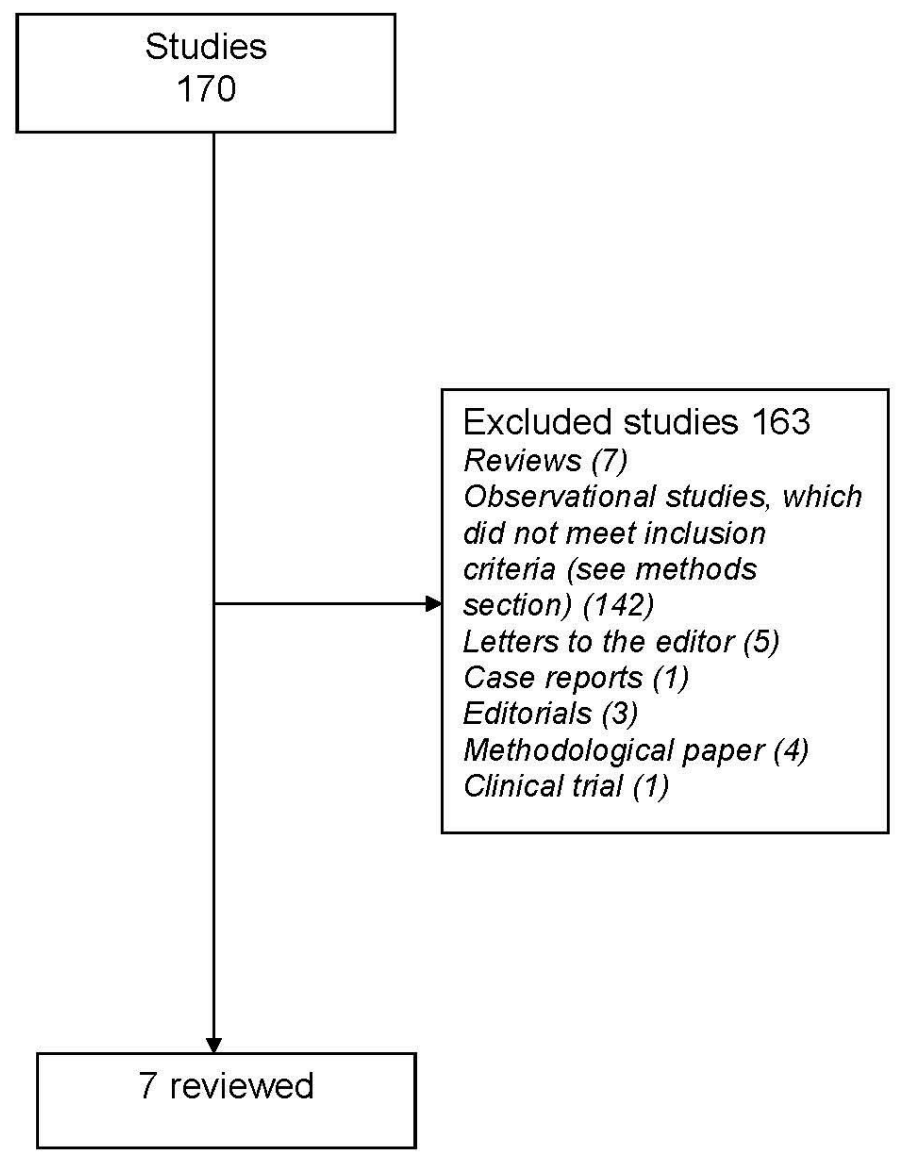


